\author{
A.R. Yeshkeyev, M.T. Omarova, G.E. Zhumabekova \\ Ye.A. Buketov Karaganda State University, Kazakhstan \\ (E-mail: modth1705@mail.ru)
}

\title{
The $J$-minimal sets in the hereditary theories
}

\begin{abstract}
Our attention in given article will be paid to the study of model-theoretic properties of hereditary Jonsson theories, while we consider Jonsson theories that retain jonsonness under any admissible enrichment. In given paper new concepts of «essential type», «essential geometric base» are introduced, the orbital types and strongly minimal sets within the framework of special subsets of the semantic model, on which a closure operator is given, defining the special geometry of Jonsson are considered. The results for the $J$-strongly minimal types of the semantic model in the case, when these sets are separated from the orbits of the central types of Jonsson hereditary theories are also obtained.
\end{abstract}

Keywords: Jonsson theory, semantic model, hereditary theory, $J$-minimal set, $J$-strongly minimal set, permissible enrichment, central type, orbital type, essential type.

It is well known that any first-order theory can be transformed in easy way to Jonsson theory. Thus, if we consider some model of an arbitrary signature, then the choice of all Jonsson theories of this model in the special class is a natural admissibility, and the study of the model-theoretic properties of such class is undoubtedly actual problem. This is due to the fact that in the classical model theory there are historically established two approaches to the study of theories and their classes of models. In the first case, a class of complete theories is usually considered and, correspondingly, their models are studied. In the second case, we consider a class of theories, generally speaking incomplete theories, but with some additional properties, while naturally there are limitations and under study to the classes of models of such theories. Today, more research in model theory is associated with the study of model-theoretic properties of a class of theories of the first kind, i.e. complete theories, as well and the study of their classes of models.

An essential example of the theory from the second case is the class of inductive theories of a fixed signature, and this class has a subclass of Jonsson theories that define natural algebraic conditions, this subclass was so named after a well-known expert in the field of universal algebra and model theory of B. Jonsson. Among the theories of Jonsson, perfect theories of Jonsson are best studied [1]. Since Jonsson theories as a rule, are incomplete, and isomorphic embedding and various kinds of homomorphisms are considered as morphisms [2], the technical apparatus of the study of such theories is less developed than the apparatus of studying complete theories, in connection with the transfer of ideas, concepts and, correspondingly, results from the field of complete theories [3, 4] in the field of Jonsson theories, of course, is an interesting challenge. Model-theoretic properties of this class are good enough studied both from the standpoint of model theory and from the side of universal algebra, and many classical examples of classes of algebra satisfy the requirements of this subclass, namely, Jonsson conditions. Our attention in this article will be paid specifically to the study of model-theoretic properties of theories for this class and the corresponding classes of models. As it turned out, in the case of perfect Jonsson theories, it is enough to study the classes of existentially closed models of these theories. In arbitrary case, Jonsson theory always has some semantic invariant - the semantic model of this theory. Correspondingly, there is a syntactic invariant - the elementary theory of given semantic model. The natural interest is the study of special formula subsets of this semantic model. In the case when the pregeometry given on the set of all subsets of the considered semantic model is modular, and the enrichment of the language saves the properties of jonssonnes and some other important model-theoretic properties (for example, the definability of the type for the considered type of stability), we will deal with admissible and hereditary types of enrichments of Jonsson theory.

In this article, given problem is considered with respect to special kinds of enrichments of the signature and wherein the received central types.

Since our main goal in this article is to consider special properties of central types, we will work with some enrichments of signatures in which some fixed Jonsson theory is given. As it turned out, not all enrichments 
preserve the property of the jonssonnes of the theory. In this regard, we will consider only those Jonsson theories that retain their jonssonnes with any enrichment of the signature. We shall call such Jonsson theories hereditary. In some cases, the requirement of modularity for the Jonsson theory is sufficient to keep it conserved.

We give the basic necessary definitions of concepts and associated with them the obtained previously results. Let $T$ be a some Jonsson theory, $C$ be its semantic model.

Definition 1 [5; 289]. Let $C$ be as above and let cl: $P(C) \rightarrow P(C)$ be an operator on the power set of $C$. We say that $(C, c l)$ is a pregeometry if the following conditions are satisfied.

i) If $A \subseteq C$, then $A \subseteq \operatorname{cl}(A)$ and $\operatorname{cl}(\operatorname{cl}(A))=\operatorname{cl}(A)$.

ii) If $A \subseteq B \subseteq C$, then $\operatorname{cl}(A) \subseteq \operatorname{cl}(B)$.

iii) (exchange) if $A \subseteq C, a, b \in C$ and $a \in \operatorname{cl}(A \cup\{b\})$, then $a \in \operatorname{cl}(A), b \in \operatorname{cl}(A \cup\{a\})$.

iv) (finite character) if $A \subseteq C$ and $a \in \operatorname{cl}(A)$, then there is a finite $A_{0} \subseteq A$ such that $a \in \operatorname{cl}\left(A_{0}\right)$.

We say that $A \subseteq C$ is closed if $\operatorname{cl}(A)=A$.

If $D$ is strongly minimal, we can associate a pregeometry by defining $\operatorname{cl}(A)=\operatorname{acl}(A) \cap D$ for $A \subseteq D$.

We can generalize basic ideas about independence and dimension from strongly minimal sets to arbitrary pregeometries for any subset of fix semantic model of some Jonsson theory.

Let as call $(X, c l)$ - Jonsson pregeometry (further $J$-pregeometry) if $X \subseteq C$ and $C$ and $T$ as above.

Definition 2. If $(X, c l)$ is a Jonsson pregeometry, we say that $A$ is Jonsson independent if $a \notin \operatorname{cl}(A \backslash\{a\})$ for all $a \in A$ and that $B$ is a $J$-basis for $Y$ if $B \subseteq Y$ is $J$-independent and $Y \subseteq \operatorname{acl}(B)$.

Definition 3. We say that a $J$-pregeometry $(X, c l)$ is $J$-geometry if $c l(\emptyset)=\emptyset$ and $\operatorname{cl}(\{x\})=\{x\}$ for any $x \in X$.

If $(X, c l)$ is a $J$-pregeometry, then we can naturally define a $J$-geometry. Let $X_{0}=X \backslash \operatorname{cl}(\emptyset)$. Consider the relation $\sim$ on $X_{0}$ given by $a \sim b$ iff $\operatorname{cl}(\{a\})=\operatorname{cl}(\{b\})$. By exchange, $\sim$ is an equivalence relation. Let $\widehat{X}$ be $X_{0} / \sim$. Define $\widehat{c l}$ on $\widehat{X}$ by $\widehat{c l}(A / \sim)=\{b / \sim: b \in c l(A)\}$.

Definition 4. Let $(X, c l)$ be $J$-pregeometry. We say that $(X, c l)$ is trivial if $c l(A)=Y_{a \in A} c l\{a\}$ for any $A \subseteq X$. We say that $(X, c l)$ is modular if for any finite-dimensional closed $\operatorname{Jdim}(A \cup B)=\operatorname{Jdim}(A)+\operatorname{Jdim}(B)-$ $-\operatorname{Jdim}(A \cap B)$.

We say that $(X, c l)$ is locally modular if $\left(X, c l_{a}\right)$ is modular for some $a \in X$.

Definition 5. We say that $(X, c l)$ is modular if for any finite-dimensional closed $A, B \subseteq X$

$$
\operatorname{dim}(A \cup B)=\operatorname{dim} A+\operatorname{dim} B-\operatorname{dim}(A \cap B) .
$$

Definition 6 . If $X=C$ and $(X, c l)$ is a modular, then Jonsson theory $T$ is called modular.

We work actually with the following types of sets.

Definition \%. Let $X \subseteq C$. We will say that a set $X$ is $\nabla-c l$-Jonsson subset of $C$, if $X$ satisfies the following conditions:

1) $X$ is $\nabla$-definable set (this means that there is a formula from $\nabla$, the solution of which in the $C$ is the set $X$, where $\nabla \subseteq L$, that is, $\nabla$ is a view of formula, for example $\exists, \forall, \forall \exists$ and so on);

2) $\operatorname{cl}(X)=M, M \in E_{T}$, where $c l$ is some closure operator defining a pregeometry over $C$ (for example $c l=a c l$ or $c l=d c l)$.

Definition 8. An enrichment $\bar{T}$ of the Jonsson theory $T$ is said to be permissible if any $\nabla$-type (it means that $\nabla$ subset of language $L_{\sigma}$ and any formula from this type belongs to $\nabla$ ) in this enrichment is definable in the framework of $\bar{T}_{\Gamma \text {-stability. }}$

Definition 9. Jonsson theory is said to be hereditary, if in any of its permissible enrichment, any expansion of it in this enrichment will be Jonsson theory. $E_{T}$.

Let $S_{\nabla}^{(1)}(X)$ be the set of all complete 1-types over the set $X$, formulas which belong to $\nabla$. Let $X \subseteq M, M \in$

Definition 10. Type $p \in S_{\nabla}^{(1)}(X)$ is called essential if for any set $Y, Y \subseteq N, N \in E_{T}$, such that $X \subseteq Y$ in $T$ exists only unique type $q \in S_{\nabla}^{(1)}(Y)$ and the type $q$ is a $J$-nonforking extension of type $p$.

Let $p, q \in S_{\nabla}^{(1)}(X), \mathfrak{A} \in E_{T}$ and $X \subseteq A$. The relation $p \leq_{A} q$ is means that for any model $\mathfrak{B} \in E_{T}$, such that $\mathfrak{B} \supseteq \mathfrak{A}$, from the realizability of $q$ in $B \backslash A$ implies the realizability of $p$ in $B \backslash A$. The relation $p \equiv q$ means that for any model $\mathfrak{A} \in E_{T}, X \subseteq A$, has $p \leq_{A} q$ and $q \leq_{A} p$. We denote the set $\left\{q \mid q \in S_{\nabla}^{(1)}(X), p \equiv q\right\}$ by $[p]$, and the set $\left\{[p] \mid p \in S_{\nabla}^{(1)}(X)\right\}$ denote by $S_{\nabla}^{(1)}[X]$. We write $[p] \leq_{A}[q]$, if $p \leq_{A} q$. The types $p, q$ are called independent if for any $\mathfrak{A} \in E_{T}, X \subseteq A$, don't have a place neither $p \leq_{A} q$, nor $q \leq_{A} p$. If $p$ and $q$ are independent, then we say that $[p]$ and $[q]$ are independent. 
The following definition gives the concept of a basis among the above types.

Definition 11. The set $B=\left\{\left[p_{i}\right] \in S_{\nabla}^{(1)}[X] / i \in I\right\}$ is called base for $S_{\nabla}^{(1)}[X]$ if:

(1) $\left[p_{i}\right]$ and $\left[q_{j}\right]$ independent for $i \neq j$;

(2) for any $[q] \in S_{\nabla}^{(1)}[X]$ and $\mathfrak{A} \in E_{T}, X \subseteq A$, exists $i \in I$ such that $\left[p_{i}\right] \leq_{A}[q]$

Definition 12. The base of the theory $T$ is the base for $S_{\nabla}^{(1)}[\varnothing]$ (if it exists). The base $B$ of theory $T$ is called essential if for any $[p] \in B$ exists an essential type $q \in[p]$.

Definition 13. We will call the essential base of the types of Jonsson theory $T$ geometric if the following conditions are satisfied:

1) $\forall p \in S_{\nabla}^{(1)}(X)$, where $X \subseteq C, C$ as above and $(C, c l)-J$-geometry;

2) the concept of independence in the sense of geometry generated by a strongly minimal central type will coincide with the concept of independence $(C, c l)$ - J-geometry (coincidence of the concept of a base in terms of strong minimality, pregeometry and central types that form an essential base, wherein the orbits of the central types that are their solutions in the semantic model).

It is necessary to take into account the condition of completeness of the considered theories order to after enrichment they can be associated with their central types (they are complete). In [6] the class of existentially closed models and the properties of a forking on a subset of these models are considered. The types considered in this paper were complete existential types. In this connection, we will notice, that we need $\exists$-completeness for the theories under consideration, and the fact, that independence in the sense of forking in [6] for existentially closed models is consistent with independence in the sense of geometry mentioned above.

In [7], the notion of Jonsson spectrum for abelian groups was considered. We want to define the concept of Jonsson spectrum for an arbitrary case.

Let $\mathfrak{A}$ be an arbitrary model of some fixed signature $\sigma$.

Then the $\operatorname{JSp}(\mathfrak{A})=\{T \mid \mathfrak{A} \in \operatorname{ModT}, T$ - Jonsson theory of the signature $\sigma\}$ is the Jonsson spectrum of the model $\mathfrak{A}$. We will say that two models $\mathfrak{A}, \mathfrak{B}$ are cosemantic among themselves if they have the same semantic model. Symbolically $\mathfrak{A} \bowtie \mathfrak{B}$. It is easy to understand that this relation $\bowtie$ is the equivalence relation between models, which generalizes the concept of elementary equivalence [2]. Therefore we consider the factor set $J \operatorname{Sp}(\mathfrak{A}) / \bowtie$ for the model $\mathfrak{A}$.

Further we will work only with permissible enrichments and we will consider such enrichments for the Jonsson spectrums, which consist only of hereditary Jonsson theories.

Consider some enrichment of the signature $\sigma$ and consider the central type of this enrichment for all Jonsson theories $T \in J S p(\mathfrak{A})$.

Let $C$ be the semantic model of the theory $T, A \subseteq C$. Let $\sigma_{\Gamma}=\sigma \bigcup \Gamma$, where $\Gamma=\{P\} \bigcup\{c\}$. Let $\bar{T}=$ $T h_{\forall \exists}\left(C, c_{a}\right)_{a \in C} \bigcup T h_{\forall \exists}\left(E_{T}\right) \bigcup\{P(c)\} \bigcup\{" P \subseteq "\}$, where $\{" P \subseteq "\}$ is an infinite set of sentences expressing the this fact that the interpretation of the symbol $P$ is an existentially closed submodel in the language of the signature $\sigma_{\Gamma}$. I.e. the interpretation of the symbol $P$ is the solution of the following equation $P(C)=M \in E_{T}$ in the language $\sigma_{\Gamma}$. By virtue of the hereditary of the theory $T$ the theory $\bar{T}$ will be a Jonsson theory. Consider all the completions of the theory $\bar{T}$ in the signature language $\sigma_{\Gamma}$. Since $\bar{T}$ is a Jonsson theory, it has its center, and we denote it by $\bar{T}^{*}$ and this center is one of the above completions of the theory $\bar{T}$. At restriction of the signature $\sigma_{\Gamma}$ to $\sigma \cup P$, due to the laws of first-order logic, since the constant $c$ already does not belong to this signature, we can replace this constant on a symbol of variable, for example $x$. And then the theory $\bar{T}^{*}$ becomes a complete 1-type for the variable $x$. This type we will call the central type of the theory $\bar{T}$ in this enrichment. This enrichment is denoted by $\odot$.

Next, we will be back to $J S p(\mathfrak{A}) / \bowtie$ for the model $\mathfrak{A}$ of an arbitrary signature and consider the admissible enrichment of this signature with the help of a predicate and a constant and consider the central type for each theory $\Delta$ from $J S p(\mathfrak{A})$.

For the $\nabla$-complete Jonsson theory, we will define the concept of $J$-strongly minimality [8].

Definition 14. Let $\mathfrak{M}$ be an existentially closed model of $T$ and $\varphi(\bar{x})$ be a non-algebraic $\nabla$-formula.

1. The set $\varphi(\mathfrak{M})$ is called $J$-minimal in $\mathfrak{M}$ if for all $\nabla$-formulas $\psi(\bar{x})$ the intersection $\varphi(\mathfrak{M}) \wedge \psi(\mathfrak{M})$ is either finite or cofinite in $\varphi(\mathfrak{M})$.

2. The formula $\varphi(\bar{x})$ is $J$-strongly minimal if $\varphi(\bar{x})$ defines a $J$-minimal set in all existentially closed extensions of $\mathfrak{M}$. In this case, we also call the definable set $\varphi(\mathfrak{M})$ is $J$-strongly minimal.

3. A non-algebraic type in $S_{\nabla}^{(1)}(T)$ containing a $J$-strongly minimal formula is called $J$-strongly minimal.

4. A Jonsson theory $T$ is $J$-strongly minimal if any its existentially closed model is $J$-strongly minimal. 
Clearly, $J$-strongly minimality is preserved under definable bijections; i.e. if $A$ and $B$ are definable subsets of $\mathfrak{M}^{k}, \mathfrak{M}^{m}$ defined by $\varphi, \psi \in \Delta$, correspondingly, such as there is a definable bijection between $A$ and $B$, then if $\varphi$ is $J$-strongly minimal so is $\psi$.

We note another useful fact in the case of a perfect Jonsson theory, if $f$ is an automorphism of the structure $C$, leaving all elements of the set $A, f \in A u t_{A}(C)$, then $f$ obviously translates into itself each $A$-definable subset and therefore translates into itself all full types over $A$, due to the saturation of the semantic model $C$. The reverse is also true: if $\bar{A}, \bar{d} \in C^{n}$, then $t p(\bar{c} / A)=t p(\bar{d} / A)$, if there exists such $f \in A u t_{A}(C)$, that $f(\bar{c})=\bar{d}$.

In a saturated model the complete $n$-types over $A$ correspond exactly to the orbits of the $n$ elements under automorphisms fixing $A$ elementwise. And correspondingly, when the theory is complete for existential sentences in the language $L$, then this is also true for existential types.

Further, it is convenient to work inside the semantic model $C$ of Jonsson theory $C$, containing all the others.

Further, any set of parameters $A$ is considered a subset in $C$. The model $M$ is a subset of $C$ that is the carrier of an existentially closed substructure. This means that any $L(M)$ - existential formula $\varphi(x)$, satisfable in $C$, also holds on some element from $M$. The parameters of formulas further always belong to $C$, and we write $=\varphi$ if $C \models \varphi$.

The following fact is well known.

Lemma. A definable set $D$ is definable over the set $A$, if it is invariant with respect to all automorphisms of the model $C$, leaving in place each element from $A$. (Let's call them automorphisms over $A$ )

It follows that the definable closure $d c l(A)$ of the set $A$, i.e. the set of all elements definable over $A$, coincides with the set of elements invariant with respect to all automorphisms over $A$.

The element $b$, contained in a finite $A$-definable set, is called algebraic over $A$. It follows that an element $b$ is algebraic over $A$, if it has only a finite number of conjugates over $A$.

The set $\operatorname{acl}(A)$, consisting of all elements algebraic over $A$, is called the algebraic closure of the set $A$.

Next, we will consider in the language of concepts of a pure pair [9] the concept of the above-mentioned central type and, correspondingly, model-theoretic concepts (for example, stability and nonforking type extensions) with this connection.

The approach to types through automorphisms of a saturated model has been known for a long time, but this was determined, firstly, for complete types and for complete theories.

In our case, after the above enrichment, we are dealing with the central types (they are complete) of Jonsson theories and Jonsson theories, which are complete for the $\nabla$ - sentences.

Instead of a monster model, we turn to the semantic model of some Jonsson theory and then consider its automorphism group.

We give definition of some important model-theoretic concepts in the language pure pair $(A, G)$, where $A$ is some subsets of the semantic model and $G$ is automorphism group of semantic model.

Let $(A, G)$ be an arbitrary pure pair $X \subseteq A$.

1. $G_{x} \leftrightarrows\{g \in G: \forall x \in X(g(x)=x)\}$. It is obvious that $G_{x} \subseteq G$.

2. If $Y \subseteq A$ then $G_{x}(Y) \leftrightharpoons\left\{g(Y): g \in G_{x}\right\}$. If $Y=\{a\}$ then we will use the record $G_{x}(a)$. $G_{x}(Y)$ is called $G_{x}$ orbit $Y$.

3. If $0<n<\omega$ then $O^{n}(X) \leftrightharpoons\left\{G_{x}\left(\bar{a}: \bar{a} \in A^{n}\right)\right\}$.

4. $\operatorname{acl}(X) \leftrightharpoons\left\{a \in A:\left|G_{x}(a)\right|<\omega\right\}$.

5. The sequence $E=\left\langle\bar{e}_{i}: i<A\right\rangle$ finite sequences (tuples) the same length is called indistinguishable over $X$ if:

a) $\bar{e}_{i} \neq \bar{e}_{j}$ for all $i<j<a$;

b) for any sequence $\left\langle i_{k}: k<m<\omega\right\rangle$ indices such as $i_{k}<i_{s} \Leftrightarrow k<s$ for all $k, s \leq m$ exist $g \in G_{x}$ such as $g\left(\left\langle e_{k}: k \leq m\right\rangle\right),\left\langle e_{i_{k}}: k \leq m\right\rangle$.

6. If $(I ;<)$ is linearly ordered set of indices, then the sequence $E=\left\langle\bar{e}_{i}: i \in I\right\rangle$ is called indistinguishable over $X$ if for all $I_{0} \subseteq I$ such as $\operatorname{ord}\left\langle I_{0}=\omega\right\rangle, E=\left\langle e_{i}: i \in I\right\rangle$ is indistinguishable over $X$ sequence.

7. The set $E=\left\langle\bar{e}_{i}: i \in I\right\rangle$ sequences of the same length are said to be indistinguishable over $X$ if:

a) $\bar{e}_{i} \neq \overline{e_{j}}$ herewith $i \neq j$;

b) for any $F, D \subseteq E$ such as $|F|=|D|<\omega$ and any bijection $\psi: F \rightarrow D$ exist $g \in G_{x}$ such as $\psi \in g$

8. If $X \subseteq Y, p \in O^{n}(Y)$ then $p$ is called:

a) splitting over $X$ if there exist such $\bar{a}, \bar{b} \in Y$ that $G_{x}(\bar{a})=G_{x}(\bar{b})$, but for any $\bar{c} \in p G_{x \cup \bar{c}}(\bar{a}) \cap G_{x \cup \bar{c}}(\bar{b})=$ $=\bar{c} \in p(\phi)$

b) strictly splitting over $X$ if there exist such an indistinguishable over $X$ infinite sequence $E=\left\langle\bar{a}_{i}: i\langle\omega\rangle\right.$ in $A$ that $\bar{a}_{0}, \bar{a}_{1} \in Y$ and for any $\bar{c} \in p$ occurs $G_{x \cup \bar{c}}(\bar{a}) \cap G_{x \cup \bar{c}}(\bar{b})=\bar{c} \in p(\phi)$; 
c) branching over $X(p \curlywedge X)$ if there is such $Z \supseteq Y$ that $|Z \backslash Y|<\omega$ and for any $q \in O^{n}(Z)$ from the fact that $q \leq p$ follows that $q$ is strictly splitting over $X$.

9. Subset $X \subseteq A$ is called $\lambda$ - saturated if $\forall Y \subseteq X, \forall p \in O^{1}(Y)<\lambda \Rightarrow X \cap p \neq(\phi)$

10. Pure pair $(A, G)$ is called $\lambda$ - stable if $\forall X \subseteq A\left(|X| \leq \lambda \Rightarrow\left|O^{1}(X)\right| \leq \lambda\right)$.

11. Let $O(A) \leftrightharpoons \bigcup\left\{\bigcup_{n<\omega} O^{n}(X):|X|<|A|\right\}$.

By induction, we define the rank function $L: O(A) \rightarrow \operatorname{Or} d \cup\{\infty\}$ :

a) $L(p) \geq 0$ for all $p \in O(A)$;

b) if $\alpha$ is the limit ordinal then $L(p) \geq a$ if $L(p) \geq \beta$ for all $\beta<\alpha$;

c) if $\alpha=\beta+1, p \in O^{n}(X)$ then $L(p) \geq \alpha$ if $L(p) \geq \beta$ and there exists such $Y \subseteq A, q \in O^{n}(Y)$ that $X \subseteq Y$, $q \subseteq p, L(q) \geq \beta$ and $q \curlywedge X$

d) $L(p)=\alpha \Leftrightarrow L(p) \geq \alpha \vee L(p) \nsupseteq \alpha+1$;

e) $L(p)=\infty \Leftrightarrow L(p) \geq \alpha$ for all ordinals $\alpha$.

12. If $\bar{a}, \bar{b} \in A^{n}$ then $\vec{v}(\bar{a}, X)=\vec{v}(\bar{b}, X)$ means that there exists such $Y, p \in O^{n}(Y)$ that $X \subseteq Y$, $Y \omega X \subseteq Y$ is saturated $p \curlywedge X, \bar{a}, \bar{b} \in p$.

13. $V^{n}(X) \leftrightharpoons\left\{\vec{v}\left(\bar{a}, X ; \bar{a} \in A^{n}\right\}, V(X)=\bigcup_{n<\omega} V^{n}(X)\right.$ If $p \in O^{n}(X)$ then $\left.V_{p} \leftrightharpoons\{\vec{v} \bar{a}, X): \bar{a} \in p\right\}$.

14. If $X \subseteq Y, \vec{\omega} \in V^{n}(X), \vec{u} \in V^{n}(Y)$ then

$\vec{\omega}<\vec{u} \leftrightharpoons \forall \bar{a}, \bar{b} \in A^{n}\left(\vec{\omega}=\vec{v}(a, X) \vee \vec{u}=\vec{v}(\bar{b}, Y) \Rightarrow \vec{v}(\bar{a}, X)=\vec{v}(\bar{b}, X) \wedge G_{\gamma}(\bar{b}) \curlywedge X\right)$.

15. The sequence $\left\langle\bar{a}_{i}: i\langle a\rangle\right.$ is called the Morley sequence over $X$, generated $\bar{u}$ from $V^{n}(X)$ if $\vec{u}<\vec{v}\left(\bar{a}_{i}, X \cup \bigcup_{j<i} \bar{a}_{j}\right)$ for all $i<a$.

16. Let's call $\vec{u}, \vec{\omega} \in V(X)$ almost orthogonal (we denote by $\vec{u} \perp^{\alpha} \vec{\omega}$ if $\forall \overline{a,} \bar{b} \in A(\vec{u}=\vec{v}(\bar{a}, X) \wedge \vec{\omega}=$ $=\vec{v}(\bar{b}, X)) \Rightarrow G_{X \cup \bar{b}}(\bar{a}) \curlywedge X$.

17. Let's call $p, q \in O(X)$ almost orthogonal (we denote by $p \perp^{\alpha} q$ if $\vec{u} \perp^{\alpha} \vec{\omega}$ for all $\vec{u} \in V_{p}, \vec{\omega} \in V_{q}$ ).

18. Let's call $\vec{u} \in V(X), \vec{\omega} \in V(Y)$ orthogonal (we denote by $\left.\vec{u} \perp^{\alpha} \vec{\omega}\right)$ if $\forall Z \forall \vec{u}, \bar{\omega}_{1} \in V(Z)(X \cup Y \subseteq$ $\left.\subseteq Z \wedge \vec{u}<\vec{u}_{1} \wedge \bar{\omega}<\bar{\omega}_{1} \Rightarrow \vec{u}_{1} \perp^{\alpha} \bar{\omega}_{1}\right)$

19. Let's call $p \in O(X), q \in O(Y)$ orthogonal (we denote by $p \perp q)$ if $q \subseteq V_{p} \forall \vec{\omega} \in V_{q}(\vec{u} \perp \vec{\omega})$.

20. Let's call $p \in O(X)$ regular if $\forall Y \forall q \in O(Y)(X \in Y \wedge q \subseteq p \wedge q \curlywedge X \Rightarrow p \perp q)$.

All concepts introduced in this way related to nonforking extensions of types of Jonsson theory naturally give Jonsson analogs of theorems for complete theories.

Let the above permissible enrichment of Jonsson spectrum $J S p(A) / \bowtie$ of an arbitrary model $\mathfrak{A}$ of some fixed signature $\sigma$ be given. Moreover, $\operatorname{PJSp}(A) / \bowtie \subseteq J S p(A) / \bowtie$ is a perfect Jonsson spectrum, i.e. those Jonsson theories of the $\mathfrak{A}$ model are perfect. Also among the theories from $J S p(A) / \bowtie$ we choose those theories that are $\nabla$ - complete, $\nabla$ - is the type of formulas of the type $\forall, \exists, \forall \exists$. Thus, we will work with both perfect and not perfect Jonsson theories, but only theories from the class $\nabla$-complete and hereditary.

When working with existentially closed models by fixed Jonsson theory, the following well-known fact is important.

Theorem 1 [10; 185]. Let $L$ be a first-order language and $T$ be a theory in $L$. Suppose that $T$ has JEP, and let $A, B$ be e.c. models of $T$. Then every $\forall_{2}$ sentence of $L$ which is true in $A$ is true in $B$ too.

Consider the class $[T] \in J S p(A) / \bowtie$ and $T h_{\forall \exists}\left(E_{\Delta}\right)=T_{0}$ (an analog of the Kaiser hull), where $\Delta \in[T]$. It is clear that this theory is Jonsson and also belongs to [T]. Let $\bar{T}_{0}$ be the enrichment of $T_{0}$ in the enrichment of $\odot$. Then its center is $\bar{T}_{0}^{*}$ and $P_{\Delta}^{c}$ is its central type. Correspondingly, all Jonsson theories $\Delta \in[T]$ have their corresponding types, which we will denote by $p_{\Delta}^{c}$. Let $T h(C)$ (where $C$ is a semantic model of class $[T]$ ) denote by $\mathbb{T}$ and correspondingly $\overline{\mathbb{T}}$ is the enrichment of $\mathbb{T}$ and $\overline{\mathbb{T}}^{*}$ is the center of $\overline{\mathbb{T}}, P_{\mathbb{T}}^{C}$ is its center type. Thus, we can consider the class of central types for each Jonsson theory $\Delta \in[T]$, and we denote this class by $\mathbb{P}_{[T]}^{C}$, and moreover $P_{\mathbb{T}}^{C} \in \mathbb{P}_{[T]}^{C}$. Note that for perfect Jonsson theories $\Delta \in[T]$ their central types are equal to each other.

Consider an essential geometric base consisting of central types for the case when the orbits of these central types distinguish $J$-strongly minimal subsets of the semantic model $C$. And let the orbital central types form a base in the sense of $C-c l$ geometry, where $c l=a c l, c l=d c l$ on $J$ - strongly minimal subsets of the semantic model $C$.

Within the above sets of types, we get the following result:

Let $T$ be a $\Delta$ - complete hereditary Jonsson theory in the above enrichment $\odot, C$ - its semantic model.

Theorem 2. For any $\Delta \in[T], \nabla=\exists$, if $\psi(x) \in \nabla$ is a formula of $L$, then the following is equivalent.

(a) $\psi(A)$ is $J$-strongly minimal, $A \in E_{\Delta}$;

(b) for every existentially closed model $B \in E_{\Delta}, \psi(B)$ is $J$-minimal in $B$; 
(c) $\psi(C)$ is $J$-minimal in $C$.

Proof. (b) implies (a) by the definitions, and (a) implies (c) since one can note that $A$ as existentially closed submodel of $C$. To complete the proof it suffices to show that if $C$ is $\omega-\nabla$-saturated (it means that saturateness regarding $\nabla$-types) and $\psi(C)$ is $J$-minimal in $C$, then $\psi(C)$ is $J$-strongly minimal in $C$. (When $T$ is perfect, we know that $C$ is $\omega-\nabla$-saturated) if $T$ not perfect then $\bar{T}$ not perfect, but $\psi(C) J$-minimal in $C$ which means that it has no more than a countable number $\nabla$-type. Then model has $\omega-\nabla$-saturated model. Suppose to the contrary that $B$ is an elementary extension of $C$ and there is a formula $\phi(x, \bar{b})$ with parameters $\bar{b}$ in $B$, such as $\psi(B) \cap \phi(B, \bar{b})$ and $\psi(B) \backslash \phi(B, \bar{b})$ are both infinite. (Here we are temporarily dropping the assumption that every model is an elementary substructure of $C$.) Let $\bar{a}$ be the parameters of $\psi$. By virtue of Theorem 1, $(C, \bar{a}) \underset{\forall \exists}{\bar{\forall}}(B, \bar{a})$. Then since $C$ is $\omega-\nabla$-saturated, there is a tuple $\bar{c}$ in $C$ such as $(C, \bar{a}, \bar{c}) \underset{\bar{\forall}}{\bar{\forall}}(B, \bar{a}, \bar{b})$. This implies that both $\psi(C) \cap \phi(C, \bar{c})$ and $\psi(C) \backslash \phi(C, \bar{c})$ are infinite, contradicting the assumption that $\psi(C)$ is $J$-minimal in $C$.

Theorem 3. For every $\Delta \in[T], P_{\mathbb{T}}^{C} \in \mathbb{P}_{[T]}^{C}$ if $P_{\mathbb{T}}^{C}$ is $J$-strongly minimal non-algebraic type, then $p_{\Delta}^{c}$ will be $J$-minimal non-algebraic type.

Proof. The proof follows from Theorem 2.

All concepts that are not defined in this article can be extracted from [1].

\title{
References
}

1 Ешкеев А.Р. Йонсоновские теории и их классы моделей: моногр. / А.Р. Ешкеев, М.Т. Касыметова. - Караганда: Изд-во КарГУ, 2016. - 346 с.

2 Poizat B. Positive Jonsson Theories / B. Poizat, A.R. Yeshkeyev // Logica Universalis. - 2018. - Vol. 12, No. 1-2. - P. 101-127.

3 Yeshkeyev A.R. Properties of lattices of the existential formulas of Jonsson fragments / A.R. Yeshkeyev, M.T. Kasymetova // Bulletin of the Karaganda University. Mathematics series. - 2015. - Vol. 79, No. 3. - P. 25-32.

4 Yeshkeyev A.R. On lattice of existential formulas for fragment of Jonsson set / A.R. Yeshkeyev, O.I. Ulbrikht // Bulletin of the Karaganda University. Mathematics series. - 2015. - Vol. 79, No. 3. P. 33-39.

5 Marker D. Model Theory: In introduction / D. Marker. - Springer-Verlag. New York. Inc., 2002. - P. 342.

6 Pillay A. Forking in the category of existentially closed structures / A. Pillay. Connection between Model Theory and Algebraic and Analytic Geometry (A. Macintyre, ed), Quaderni di Matematica 6, 2000.

7 Ешкеев А.Р. $J S p$-косемантичность и $J S B$ свойство абелевых групп / А.Р. Ешкеев, О.И. Ульбрихт // Siberian Electronic Mathematical Reports [Электронный pecypc]. - Режим доступа: http://semr.math. nsc.ru. Вып. 13(2016). - C. 861-874.

8 Yeshkeyev A.R. Strongly minimal Jonsson sets and their properties / A.R. Yeshkeyev // Bulletin of the Karaganda University. Mathematics series. - 2015. - Vol. 80, No. 4. -P. 47-51.

9 Ешкеев А.Р. Йонсоновские множества и их некоторые теоретико-модельные свойства. - Караганда: Изд-во КарГУ, 2014.

10 Hodges W. A shorter model theory / W. Hodges. - Cambridge: Cambridge University Press, 1997. P. 310

\section{А.Р. Ешкеев, М.Т. Омарова, Г.Е. Жумабекова}

\section{Мұралы теориялардағы $J$-минималды жиындар}

\begin{abstract}
Мақалада басты назар мұралы йонсондық теориялардың, сонымен қатар кез келген байытуда йонсондықты сақтайтын йонсондық теориялардың модельді-теориялық қасиеттерін зерттеуге бөлінген. Авторлар «елеулі тип», «елеулі геометриялық база» сияқты жаңа ұғымдары енгізіп, арнайы йонсондық геометрияны анықтайтын тұйықталу операторы берілген семантикалық модельдің арнайы ішкі
\end{abstract}


жиындарды аясында орбиталдық типтер мен қатты минималдық жиындарды қарастырды. Және осы жиындар йонсондық мұралы теорияның орталық типінің орбитасынан алынған жағдайда семантикалық модельдегі $J$-қатты минималдық типтерге қатысты нәтижелер алынды.

Kiлm сөздер: йонсондық теория, семантикалық модель, мұралы теория, $J$-минималды жиын, $J$-қатты минималды жиын, рұқсат етілген байыту, централды тип, орбиталдық тип, елеулі тип.

\section{А.Р. Ешкеев, М.Т. Омарова, Г.Е. Жумабекова}

\section{$J$-минимальные множества в наследственных теориях}

В статье уделено внимание изучению теоретико-модельных свойств наследственных йонсоновских теорий, при этом рассмотрены йонсоновские теории, которые сохраняют йонсоновость при любом допустимом обогащении. Авторами введены новые понятия «существенный тип», «существенная геометрическая база», рассмотрены орбитальные типы и сильно минимальные множества в рамках специальных подмножеств семантической модели, на которых задан оператор замыкания, определяющий специальную йонсоновскую геометрию. Также получены результаты для $J$-сильно минимальных типов семантической модели в случае, когда эти множества выделены из орбит центральных типов йонсоновских наследственных теорий.

Ключевые слова: йонсоновская теория, семантическая модель, наследственная теория, $J$-минимальное множество, $J$-сильно минимальное множество, допустимое обогащение, центральный тип, орбитальный тип, существенный тип.

\section{References}

1 Yeshkeyev, A.R., \& Kassymetova, M.T. (2016). Yonsonovskie teorii i ikh klassy modelei [Jonsson theories and their classes of models]. Karaganda: Izdatelstvo KarHU [in Russian].

2 Poizat, B., \& Yeshkeyev, A.R. (2018). Positive Jonsson Theories. Logica Universalis, Vol. 12, 1-2, 101127.

3 Yeshkeyev, A.R. \& Kassymetova, M.T. (2015). Properties of lattices of the existential formulas of Jonsson fragments. Bulletin of the Karaganda University. Mathematics series, Vol. 79, 3, 25-32.

4 Yeshkeyev, A.R. \& Ulbrikht, O. I. (2015). On lattice of existential formulas for fragment of Jonsson set. Bulletin of the Karaganda University. Mathematics series, Vol. 79, 3, 33-39.

5 Marker, D. (2002). Model Theory: In introduction. Springer-Verlag. New York. Inc.

6 Pillay, A. (2000). Forking in the category of existentially closed structures. Quaderni di Matematica 6.

7 Yeshkeyev, A.R. \& Ulbrikht, O.I. (2016). JSp-kosemantichnost i JSB svoistvo abelevykh hrupp [JSp-cosemanticnes and JSB property of abelian groups]. Siberian Electronic Mathematical Reports. Retrieved from http://semr.math.nsc.ru [in Russian].

8 Yeshkeyev, A.R. (2015). Strongly minimal Jonsson sets and their properties. Bulletin of the Karaganda University. Mathematics series, Vol. 80, 4, 47-51.

9 Yeshkeyev, A.R. (2014) Yonsonovskie mnozhestva $i$ ikh nekotorye teoretiko-modelnye svoistva [Jonsson sets and its model-theoretic properties]. Karaganda: Izdatelstvo KarHU [in Russian].

10 Hodges, W. (1997). A shorter model theory. Cambridge: University of Cambridge. 